\title{
PENINGKATAN MUTU PENANGANAN LIMBAH RUMAH SAKIT (SNI 3242:2008) DENGAN PENERAPAN TEKNOLOGI KARBONISASI
}

\section{Quality Improvement of Hospital Waste Handling (SNI 3242: 2008) with Application of Carbonization Technology}

\author{
Amos Lukas ${ }^{1}$, Suharto Ngudiwaluyo ${ }^{1}$, Ishenny Mohd Noor ${ }^{2}$ dan Himawan Adinegoro ${ }^{3}$ \\ ${ }^{1}$ Pusat Sistem Audit Teknologi, BPPT, JI.MH. Thamrin No. 8 Jakarta 10340, DKI Jakarta, Indonesia \\ ${ }^{2}$ Pusat Penelitian dan Pelatihan Teknologi Internasional Dr.Ishenny - Kota Langsa, Banda Aceh, Indonesia \\ ${ }^{3}$ Pusat Teknologi Agroindustri, BPPPT, JI.MH. Thamrin No. 8 Jakarta 10340, DKI Jakarta, Indonesia \\ e-mail: amoslukas2010@gmail.com
}

Diterima: 26 Juni 2018, Direvisi: 20 Juli 2018, Disetujui: 31 Juli 2018

\begin{abstract}
Abstrak
Pengolahan limbah yang tercantum di dalam Standar Nasional Indonesia SNI 3242:2008. meliputi kegiatan pemisahan, daur ulang dan composting. Kondisi ini masih meninggalkan sampah B3 ke rumah sakit atau ke tempat penampungan akhir (TPA). Penyelesaian masalah limbah non-B3 dan B3 harus dengan teknologi yang ramah lingkungan. Penelitian ini bertujuan untuk memberikan solusi atas penanganan limbah dari sampah domestik non-B3 maupun B3 di rumah sakit yang saat ini mengacu pada SNI 3242:2008. Penelitian ini dilakukan di Rumah Sakit Umum Kota Langsa Propinsi Aceh. Metode penelitian mencakup kajian teknologi pengolahan limbah yang dapat mengatasi limbah non-B3 dan B3, analisis biokatalis dalam menurunkan energi aktivasi den kajian teknologi karbonisasi. Hasil penelitian menunjukkan bahwa teknologi karbonisasi mampu merubah sampah non-B3 dan B3 menjadi produk yang bernilai ekonomi serta bermanfaat untuk memperbaiki lingkungan. Teknologi karbonisasi tidak menghasilkan polusi dari prosesnya sehingga layak digunakan di rumah sakit karena sesuai dengan SNI yang terkait dengan persyaratan emisi gas buang (SNI 19-7117.2-2005). Manfaat lain yang diperoleh dengan menerapkan teknologi karbonisasi adalah biokarbon, asap cair, pupuk cair, syngas dan steam (pasteurisasi di rumah sakit).
\end{abstract}

Kata kunci: standar, mutu, SNI 3242:2008, limbah, non-B3, B3, rumah sakit, teknologi karbonisasi.

\begin{abstract}
Waste treatment listed in Indonesian National Standard SNI 3242: 2008. including separation, recycling and composting activities. This condition still leaves the B3 waste to the hospital or to the final shelter (TPA). The solving of non-B3 and B3 waste problems must be with environmentally friendly technology. This study aims to provide solutions for handling waste from non-B3 or B3 domestic waste in hospitals that currently refer to SNI 3242: 2008. This research was conducted at Langsa General Hospital of Aceh Province. The research method includes the study of waste treatment technology that can overcome the non-B3 and B3 wastes, biocatalyst analysis in reducing the activation energy and carbonation technology study. The results show that carbonization technology is able to transform non-B3 and B3 waste into economic value and useful products improve the environment. Carbonation technology does not produce pollution from the process so it is feasible to be used in hospitals because it is in accordance with SNI related to exhaust emission requirements (SNI 19-7117.2-2005). Other benefits gained by applying carbonization technology are biocarbon, liquid smoke, liquid fertilizer, syngas and steam (pasteurization at the hospital).
\end{abstract}

Kata kunci: standard, quality, SNI 3242: 2008, waste, non-B3, B3, hospital, carbonation technology.

\section{PENDAHULUAN}

Sampah padat limbah rumah sakit adalah bahan berbahaya dan beracun (B3) menjadi masalah besar di dunia khususnya di Indonesia (Aleluia and Ferrao, 2016). Pengolahan di TPA yang dicantumkan dalam SNI 3242:2008, saat ini masih menggunakan teknologi insinerator, walaupun masih menghasilkan emisi udara yang melanggar SNI lain. Pengolahan sampah masih menghasilkan emsisi udara, biaya alat yang mahal, volume proses yang kecil, biaya operasional yang besar karena butuh bahan bakar dan tidak ramah lingkungan. Perlu segera dikembangkan teknologi pengolahan limbah rumah sakit B3 di TPA atau di rumah sakit yang ramah lingkungan, biaya operasional rendah, dan limbah yang diolah memiliki nilai ekonomi. 
Penanganan sampah limbah B3 di Indoensia masih sepenuhnya menjadi tanggung jawab pemerintah, dengan biaya pengolahan di bebankan kepada perusahaan atau rumah sakit penghasil limbah B3, akan tetapi pemerintah belum memiliki teknologi dan sumberdaya manusia untuk menangani sampah (Damanhuri, 2005). Oleh sebab itu perlu segera dicarikan solusinya dengan mengembangkan teknologi yang mampu menjawab tantangan dalam pengolahan limbah rumah sakit atau B3.

SNI 3242:2008, memuat persyaratan dan pengelolaan sampah permukiman di perkotaan untuk jenis sampah domestik non B3 dan B3 dengan menerapkan $3 R$ mulai dari kegiatan di sumber sampai dengan TPS, atas dasar SNI ini belum dapat menyelesaikan sampah secara tuntas, karena dalam prosesnya adalah penimbunan sampah dan bukan menuntaskan masalah sampah. Sumber sampah yang dimaksudkan di dalam SNI ini berasal dari lingkungan permukiman, seperti: (1) pasar kecil; (2) sekolah; (3) klinik kesehatan; (4) jalan saluran; (5) taman; den (6) tempat ibadah. Teknis operasional SNI 3242:2008, menerapkan sistem penanganan sampah setempat dengan : 1) Menerapkan pemilahan sampah organik dan non organik 2) Menerapkan teknik 3R di sumber dan TPS dan 3) Penanganan residu oleh pengelola sampah kota.

B3 adalah sampah yang berasal dari aktivitas rumah tangga, mengandung bahan dan atau bekas kemasan suatu jenis bahan berbahaya dan atau beracun, karena sifat atau konsentarsinya dan atau jumlahnya, baik secara langsung maupun tidak langsung dapat merusak dan atau mencemarkan lingkungan hidup dan atau membahayakan kesehatan manusia (Setiyono, 2001). Limbah B3 dikembalikan ke produsen untuk diolah dan ditempatkan di lokasi TPA khusus B3, kondisi ini akan menyebabkan sampah B3 tetap menjadi masalah dan tidak terselesaikan masalah sampahnya.

Tujuan studi ini adalah untuk meneliti penerapan teknologi karbonisasi pada proses pengolahan limbah B3 sesuai SNI yang sudah ada dan memberikan masukan kepada SNI yang sudah ada agar mampu mengolah sampah non B3 dan B3 sampai zero waste.

\section{TINJAUAN PUSTAKA}

\subsection{Sampah Rumah Sakit}

Limbah rumah sakit adalah semua limbah Rumah Sakit dalam bentuk padat, cair, pasta (gel) maupun gas yang dapat mengandung mikroorganisme pathogen bersifat infeksius, bahan kimia beracun, dan sebagian bersifat radioaktif (Depkes, 2006).

Limbah rumah sakit cenderung bersifat infeksius dan mengandung racun yang dapat berpengaruh terhadap kesehatan manusia, memperburuk kelestarian lingkungan hidup apabila tidak dikelola dengan baik. Rumah Sakit harus mempunyai fasilitas pengelolaan limbah sendiri yang ditetapkan Keputusan Menteri kesehatan Republik Indonesia No.1204/Menkes/SK/X/2004 tentang Persyaratan Kesehatan Lingkungan Rumah Sakit dan juga mengacu pada SNI 3242:2008. Untuk itu setiap Rumah Sakit harus melakukan reduksi limbah dimulai dari sumbernya dan harus mengelola dan mengawasi penggunaan bahan kimia yang berbahaya, beracun dan setiap peralatan yang digunakan dalam pengelolaan limbah medis mulai dari pengumpulan, pengangkutan, dan pemusnahan harus melalui sertifikasi dari pihak yang berwenang.

Selain itu fasilitas pengolahan limbah cair harus dilengkapi dengan kontainer pengumpul yang sesuai dengan karakteristik bahan kimia dan radiologi, volume dan prosedur penanganan dan penyimpanannya. Rumah sakit harus memiliki Instalasi Pengolahan Air Limbah sendiri.

\subsection{Pengolahan Sampah Rumah Sakit}

SNI 3242:2008 menyerahkan mekanisme pemusnahan sampah kepada rumah sakit dan Kementerian Kesehatan mengizinkan pemusnahan sampah medis yang ada saat ini menggunakan cara pembakaran dan pada umumnya dengan teknologi insinerator, mulai dari pengangkutan sampai pada pemusnahan perlu dijaga keutuhan kemasannya. Banyak sistem pembakaran atau insinerator yang menggunakan peralatan dengan sistem mekanik. Permasalahannya adalah tidak memenuhi persyaratan SNI 19-7117.2-2005 tentang emisi yang ditimbulkan, oleh sebab itu perlu dicarikan solusi agar memenuhi persyaratan $\mathrm{SNI}$ tersebut.

Beberapa SNI yang terkait dengan rumah sakit selain SNI 3242:2008 adalah (1) Sistim, manajemen lingkungan rumah sakit harus didasarkan juga pada SNI 19-14001-2005, sistem manajemen lingkungan - Persyaratan dan panduan penggunaan, (2) SNI 19-14004-2005, sisitem manajemen lingkungan - panduan umum tentang prinsip sistem dan teknik pendung, dan (3) SNI 19-19011-2005, panduan audit sistem manajemen dan/atau lingkungan, serta memperhatikan SNI buangan emisi sebagai akibat dari pengolahan sampah.

Mengatasi sampah supaya efektif dan optimal harus diolah dengan teknologi yang 
tepat, ramah lingkungan dan menghasilkan produk yang bernilai ekonomi. Salah satu cara mutakhir dalam mengolah sampah yang ramah lingkungan (green convertion) adalah tanpa proses pemisahan antara sampah organik dan anorganik (Matsakas dkk, 2017).

Teknologi yang dikenal untuk pengolahan sampah saat ini hanya sampai level insinerasi oleh karena itu masalah sampah B3 belum bisa teratasi sesuai peraturan dan standar yang berlaku di Indonesia. Studi kasus penyelesaian masalah sampah B3 di rumah sakit Umum Langsa Kota Langsa, Propinsi Aceh NAD dengan sistem pengolahan sampah zero waste menghasilkan produk bernilai ekonomi yang bermanfaat untuk meningkatkan pendapatan masyarakat desa dan membuka lowongan kerja.

\subsection{Teknologi Pengolahan Sampah Rumah Sakit/B3}

Pengolahan limbah rumah sakit/B3, yang umum dilakukan pada saat ini adalah dengan metode: (a). sumur dalam/ sumur injeksi (deep well injection) limbah ditempatkan ke lapisan batuan yang dalam, (b) kolam penyimpanan (surface impoundments), ditampung pada kolam-kolam dan (c) landfill untuk limbah B3 (secure landfils), menempatkan limbah B3 dalam drum atau tongtong, kemudian dikubur dalam landfill yang didesain khusus untuk mencegah pencemaran limbah B3 (Asmadi, 2013). Limbah B3 tidak tuntas di proses dan suatu saat akan menjadi masalah ke lingkungan. Teknologi pengolahan sampah di TPA saat ini dilakukan dengan proses fisik, kimia dan insenerator.

\subsubsection{Proses Fisik, kimia dan solidifikasi}

Proses penambahan suatu zat dan dicampur dengan limbah untuk meminimalkan kecepatan migrasi (perpindahan) limbah untuk mengurangi toksisitas dari limbah (Klauck dkk, 2017). Solidifikasi adalah proses menggunakan aditif berdasarkan sifat fisis alami dari limbah. Peranan Aditif dalam proses stabilisasi, (1) memperbaiki karakteristik fisik limbah (2). mengurangi permukaan area yang dilalui agar dapat mengurangi kontaminan yang terjadi (3). membatasi kelarutan dari berbagai polutan yang ada di limbah dan (4). mengurangi toksisitas dari kontaminan (Shi dkk, 2017).

\subsubsection{Insinerasi}

Metode insinerasi diterapkan untuk memperkecil volume limbah rumah sakit/B3, limbah dibakar menjadi abu, kelemahannya masih gunakan bahan bakar minyak atau gas secara kontinyu serta mangalirkan udara melalui kompresor dengan rasio tertentu sesuai yang spesifikasi insenerator yang bertujuan agar pembakaran sampah dan limbah sempurna. Alat ini perlu dilakukan pengontrolan ketat agar gas beracun hasil pembakaran tidak mencemari udara. Insinerasi mampu menghancurkan jenis sampah berbahaya di mana patogen dan racun kimia bisa hancur dengan temperatur tinggi.

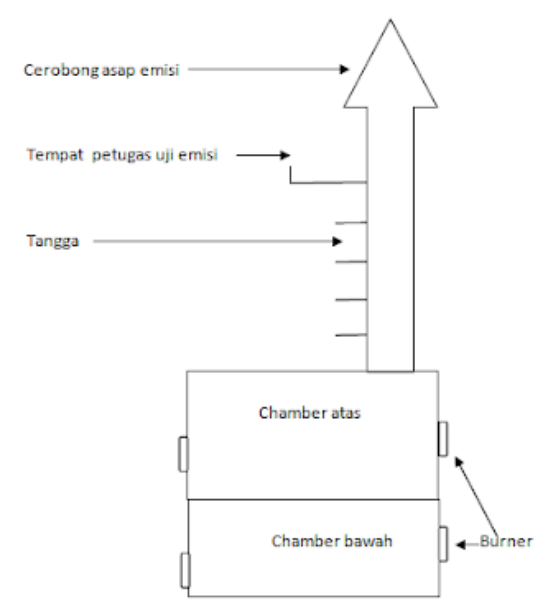

Gambar 1 Konsep desain insenerator sesuai dengan Kep.205/Bapedal/1996.

Insinerasi sangat populer di beberapa negara seperti Jepang, Denmark dan Swedia (Yan dkk, 2012). Sistem insinerasi tersebut tidak sesuai dengan SNI yang terkait dengan emisi gas buang.

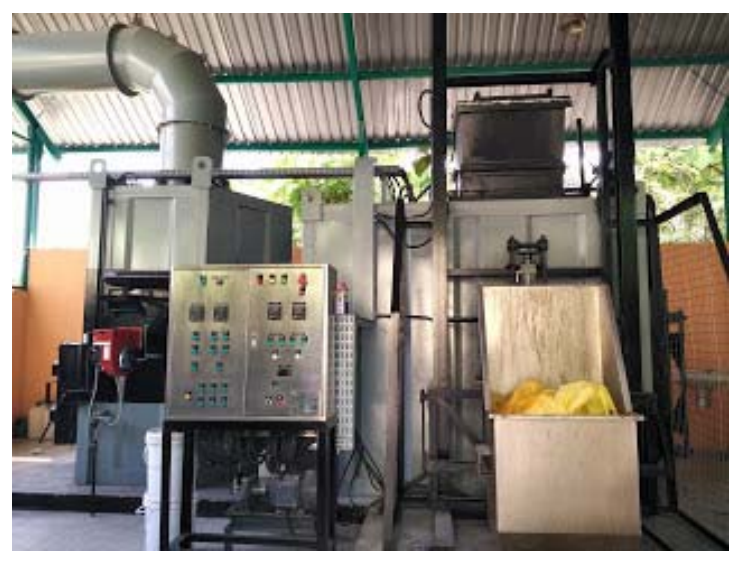

Gambar 2 Kontroler insenerator.

Proses insenerasi limbah rumah sakit/B3, dilakukan dengan teknik (a) memilah jenis sampah yang ada dan limbah/B3, (b) mengeringkan limbah dengan alat dryer, (c) membakar limbah menjadi abu yang tidak memiliki manfaat ekonomi. Reaksi pembakaran yang terjadi adalah reaksi oksidasi sebagai berikut: 

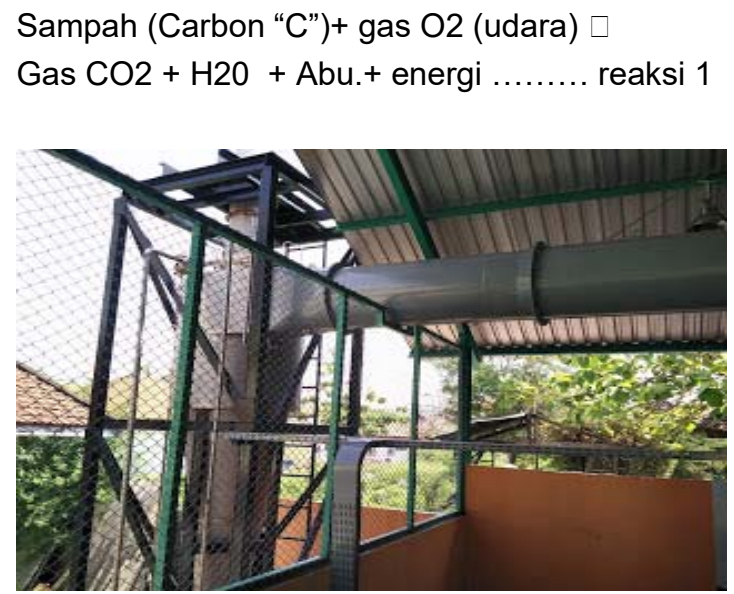

Gambar 3 Cerobong insenerator.

Konsep teknologi insenerator dikenal juga dengan nama proses oksidasi yaitu proses pembakaran sampah atau limbah B3 dengan pengaturan rasio bahan bakar dan udara yang tepat.

Beberapa kelemahan dari penerapan teknologi ini adalah (1) biaya operasinya mahal (2) sangat komplek dalam mengontrol efisiensi pembakaran dan gas buangnya (3) alat control mahal (4) memerlukan cerobong yang tinggi, (5) partikel carbon dan abu yang berukuran nano meter tetap bisa keluar dan membahayakan kesehatan dan lingkungan sekitarnya (6) efisiensi pada ruang pembakaran $40 \%$ dan (7) partikel racun yang akan lepas ke udara, tidak memenuhi SNI tentang gas emisi (Liu dkk. 2012).

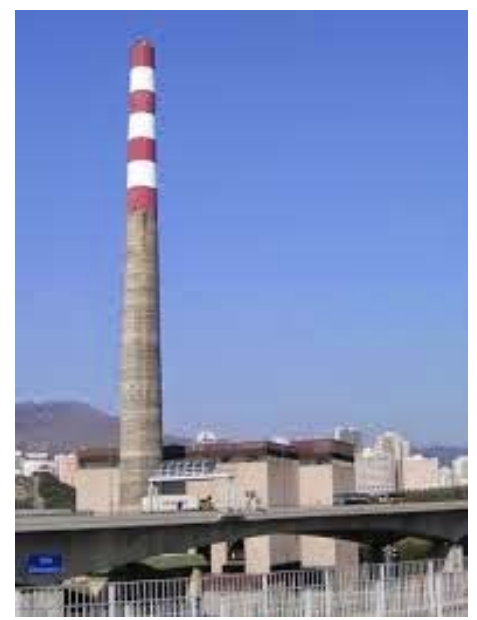

Gambar 4. Insinerator pengolahan limbah B3

Effisiensi pembakaran yang rendah karena energi aktifitas sampah atau limbah B3 tinggi sehingga tidak bisa bereaksi dengan udara (oksidasi) dan disain ruang bakar tidak mampu untuk terjadinya pembakaran sempurna. Contoh kasus inssinerator di pulau Pangkor Malaysia juga gagal membakar sampah dan limbah B3 karena masalah efisiensi pembakaran sehingga polusi udara sangat tinggi dan harus dihentikan, ironisnya biaya investasi insenerator tersebut mencapai sangat besar.

Perlu tahapan pemisahan yang juga menimbulkan tambahan biaya, waktu pengolahan yang lama sehingga terjadi tumpukan sampah yang mencemari lingkungan sekitarnya serta menjadi penyebab berbagai sumber penyakit. Kearifan lokal yang ada di masyarakat tidak pernah melakukan pemisahan sampah, oleh sebab itu perlu waktu yang lama untuk sosilisasinya atau teknologi yang sesuai dengan kondisi di Indonesia

\section{METODE PENELITIAN}

\subsection{Teknologi Karbonisasi Sampah dan limbah B3}

Teknologi karbonisasi adalah teknologi yang menggunakan radiasi panas, proses reaksi thermal tidak membutuhkan udara (Lohri dkk, 2016). Teknologi karbonisasi juga tidak membutuhkan tekanan udara sehingga tidak ada gas atau partikel yang terbang ke udara. Teknologi ini juga menghasilkan syngas yang mempunyai kalori tinggi untuk bahan bakar pembangkit listrik.

Pengolahan limbah B3 teknologi karbonisasi menguntungkan karena proses karbonisasi menghasilkan produk seperti minyak untuk energi dan biochar untuk pupuk (Wang dkk, 2017), disamping itu menghasilkan asap cair dan pupuk cair yang sangat bermanfaat untuk meningkatkan produksi tanaman padi, sawit dan aneka sayuram.

Teknologi karbonisasi memanfaatkan sampah B3 sebagai bahan bakar agar dihasilkan panas yang tinggi. Teknologi karbonisasi terdiri dari bagian reaktor dan mesin karbonisator, tekanan tetap terkontrol normal $1 \mathrm{~atm}$ dan suhu diturunkan dari $2400{ }^{\circ} \mathrm{F}$ hingga 800 ํ $\mathrm{F}$ dengan menggunakan biobatalyst fuel sebagai additive yang disemprotkan ke limbah rumah sakit yang fungsinya untuk mempermudah terjadi reaksi thermal (thermo kimia) dan produknya adalah karbon, asap cair, pupuk cair dan syngas (syntethic gas: gas Hydrogen + gas methana) (Lukas dkk, 2017).

\subsection{Biokatalis menurunkan energi aktifasi}

Biocatalyst fuel mampu menurunkan energi aktivasi limbah rumah sakit sehingga mampu menurunkan suhu reaktif sampah dari $2400{ }^{\circ} \mathrm{F}$ dengan tekanan tinggi ke suhu 800 F dengan 
tekanan normal. Kunci kerja teknologi karbonisasi adalah upaya penurunan energi aktifasi untuk meningkatkan reaksi dan effisiensi dengan bantuan biokatalis (Chen dkk, 2018).

Penerapan teknologi karbonisasi menjadi jawaban untuk pemakaian teknologi tepat guna seperti yang di syaratkan SNI 3242:2008, SNI 19-14001-2005, SNI 19-14004-2005, SNI 1919011-2005 dan beberapa SNI yang terkait dengan gas buang ke udara.

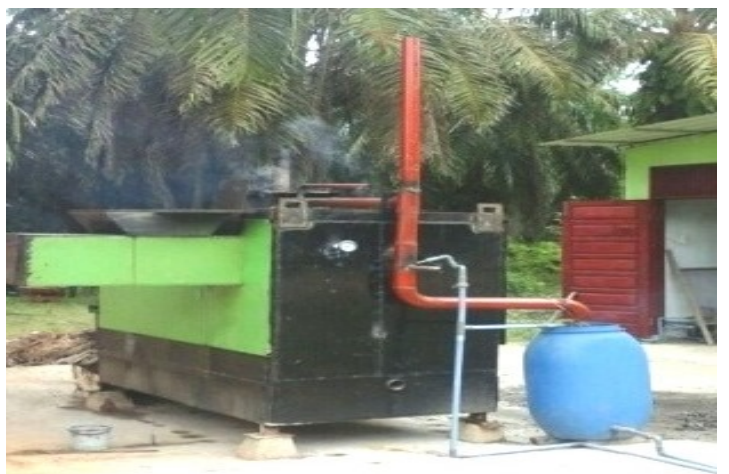

Gambar 5 Mesin karbonisasi Dr. Ishenny's.

Penanganan limbah rumah sakit sebagai studi kasus di Desa Seuriget, Kecamatan Langsa Barat, Kota Langsa, Provinsi Aceh telah sukses dilakukan secara mandiri oleh Inkubator Kampus Hijau Pusat Penelitian dan Pelatihan Teknologi Internasional Doktor Ishenny (ICH-LP3TIDI). Membuktikan teknologi karbonisasi adalah zero waste technology juga menghasilkan produk seperti media tanam, pestisida organik, bata ringan, pupuk cair, air minum sehat serta bahan bakar pembangkit listrik dan sangat sesuai SNI yang terkait dengan pengolahan sampah rumah sakit dan juga SNI yang terkait dengan emisi gas buang.

Keuntungan yang diperoleh dari pengolahan teknologi karbonisasi adalah (1) menjadikan limbah rumah sakit sebagai bahan bakar, (2) desain mesin karbonisasi adalah cubical tapi mampu beroperasi pada suhu 700 ${ }^{0} \mathrm{~F}-1000{ }^{\circ} \mathrm{F}$ tetapi tetap pada tekanan normal dan (3) mesin ini mampu menurunkan energi aktifasi sampah dan limbah sehingga terjadi reaksi thermo kimia secara sempurna pada suhu $700^{\circ} \mathrm{F}$ dan tekanan normal 1 atm. Reaksi thermo kimia seperti berikut:

Sampah + biocatalyst + Energi $\rightarrow$ Carbon $+\mathrm{H}_{2} \mathrm{O}$ (steam) + Syngas $\left(\mathrm{H}_{2}+\mathrm{CH}_{4}\right)+$ Energi..... Reaksi 2

Reaksi 2 terlihat bahwa produk utama dari karbonisasi adalah karbon dan diikuti steam pada saat sampah atau limbah masuk ke reaktor, steam tersebut akan terhidrolisa di unit hydrocyclon menjadi asap cair juga sekaligus menangkap minyak dari plastik dan partikel halus yg ikut keluar melalui hydrocyclone.

Gas buangan yang keluar adalah bersih dan tidak ada unsur racun, dioxin, furfuran, tidak berbau gas sulfide, atau ammonia atau gas tidak berwarna hitam seperti pada umumnya insinerator, memenuhi syarat yang terkait SNI emisi buang. Produk gas yang paling bernilai adalah syngas hasi reaksi thermo kimia dan gasifikasi yang berguna untuk bahan bakar pembangkit listrik generator.

Proses Karbonisasi pengolahan sampah dilakukan dengan menggunakan BFS (Bicatalyst Fuels Technology) yang merupakan produk yang memiliki paten dunia yang diproses dari minyak jelantah. Produk BSF ini memiliki keunggulan, yaitu: (a) meningkatkan kalori bahan bakar minyak, (b) pembakaran sempurna, (c) menghemat biaya maintenance, (d) mengurangi polusi dari carbon gas $\mathrm{CO}$ dan $\mathrm{CO}_{2}$ dan (e) ramah lingkungan (Noor dkk, 2012).

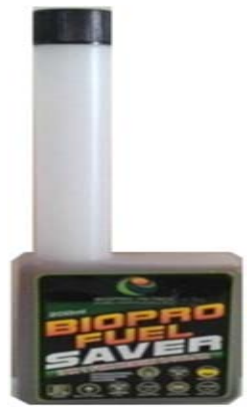

Gambar 6. BSF (Biocatalyst Fuels Technology).

\subsection{Mesin karbonisasi Dr. Ishenny's}

Teknologi karbonisasi memerlukan lokasi dengan luas $20 \times 20 \mathrm{~m}^{2}$, lebih kecil dari persyartan yang ditentukan dalam SNI 3242:2008 tidak memerlukan sistem sanitasi air lindi karena semua sampah atau limbah habis diproses dalam 24 jam dengan kapasitas 5 ton/hari per unit. Tidak ada limbah cair yang keluar dari proses karbonisasi dimana semua sampah dan limbah rumah sakit diproses menjadi produk yang berguna untuk lingkungan dan mempunyai nilai ekonomi yang tinggi, sesuai dengan SNI 1914001-2005, SNI 19-14004-2005, dan (3) SNI 19-19011-2005.

Bahan konstruksi mesin karbonisasi adalah karbon dan plat baja. Karbon digunakan sebagai isolasi panas dimana dibuat carbon blok semen yang dinamai bata karbon ringan (BATAKAR). Mampu meningkatkan panas dalam 
reaktor 95\% dengan kehilangan panas (heat losses $5 \%$ ).

Semua bahan konstruksi mesin karbonisasi direkayasa di dalam negeri. Produk karbon dikenali sebagai biokar atau emas hitam yang bermanfaat untuk memulihkan kualitas tanah pertanian, perkebunan, perikanan dan peternakan serta berguna untuk material konstruksi berupa bata karbon ringan (Cha dkk, 2016).

Produk asap cair berguna untuk biopestisida, bahan menghilangkan bau toilet, truk sampah dan tempat pembuangan sampah. Produk karbon cair juga berguna untuk kesuburan tanaman pertanian yang digunakan sebagai pupuk organik. Syngas berguna untuk bahan bakar pembangkit listrik yang akan mampu menghemat sumber bahan bakar di Indonesia.

Pengolahan limbah dengan metoda karbonisasi pertama kali beroperasi di Kota Langsa, Provinsi Banda Aceh pada tanggal 17 April 2016.

Tabel 1 Spesifikasi mesin karbonisasi.

\begin{tabular}{|c|c|}
\hline Unit & Keterangan \\
\hline Karbonisasi & $205 \mathrm{~cm} \times 101 \mathrm{~cm} \times 160 \mathrm{~cm}$ \\
\hline Reaktor & $186 \mathrm{~cm} \times 86 \mathrm{~cm} \times 100 \mathrm{~cm}$ \\
\hline Kapasitas & 5 ton / 24 jam \\
\hline Hydro cyclone & 2 smoke inlet, kap. $100 \mathrm{~L} /$ hari \\
\hline Blower Cooler & 1 Unit \\
\hline Kompresor & $1 \mathrm{HP}$ \\
\hline $\begin{array}{l}\text { Water pump } \\
\text { head }\end{array}$ & $30 \mathrm{M}$ \\
\hline Cerobong & $1 \mathrm{~m}$ (clean gas) \\
\hline
\end{tabular}

Mesin karbonisasi Dr. Ishenny's menggunakan teknologi radiasi panas atau dalam prosesnya tidak mengeluarkan bau dari gas ammonia, dioxin, asap dan sulphur dan lainnya serta tidak mengeluarkan limbah cair seperti air lindi (leachate). Sampah diproses tanpa pemilahan organik dan anorganik, tanpa perlakuan pengeringan (drying), langsung dapat diproses, sehingga terjadi penghematan biaya dan waktu.

Karbonisasi terdiri dari unit utama fungsinya mengeluarkan radiasi panas dan unit sekunder reaktor pemanasan berfungsi untuk terjadinya proses pyrolysis dan gasifikasi dan juga berfungsi memproduksi karbon aktif (biokar atau emas hitam) yang berfungsi untuk merawat atau menetralkan tanah pada $\mathrm{pH} 7.0$ yang kaya oksigen bagi perkembiakan mikro tanah yang diperlukan untuk tanah pertanian, perkebunan dan tambak perikanan untuk kembali subur dan mampu menyediakan air serta komponen NPK untuk pertumbuhan tanaman.

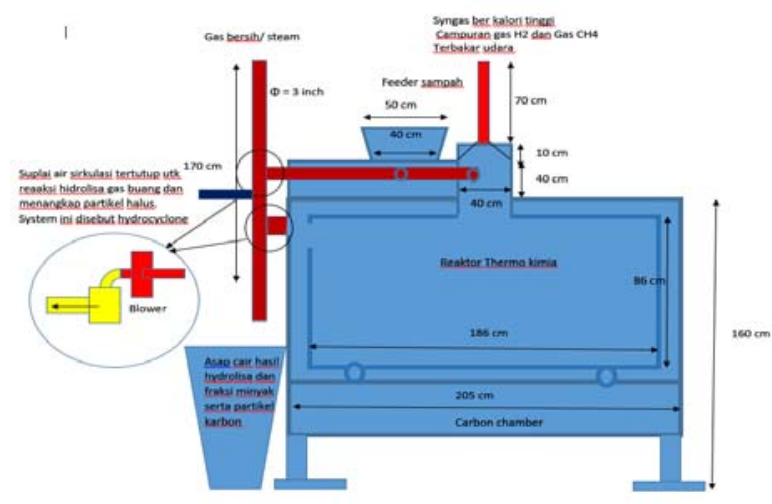

Gambar 7 Konsep desain mesin karbonisasi Dr. Ishenny's (Patented).

Mesin ini dibantu dengan dua alat yaitu: (1) kompresor untuk penyemprotan biokatalis pada sampah sebelum diproses dan (2) pompa air untuk proses pada unit hydro-cyclone unit. Peralatan karbonisasi dilengkapi unit hydrocyclone untuk menangkap asap pada tekanan rendah dan merubah phasa gas menjadi phasa cair sekaligus menghidrolisa gas dengan air. Hydrocyclone memproduksi produk yang dikenali sebagai asap cair (liquid smoke) tetapi bukan bio-oil yang dikenali selama ini.

Karbonisasi Dr. Ishenny's dengan parameter emisi gas masih berada di bawah ambang batas $\mathrm{SNI}$ yang terkait dengan emisi udara.

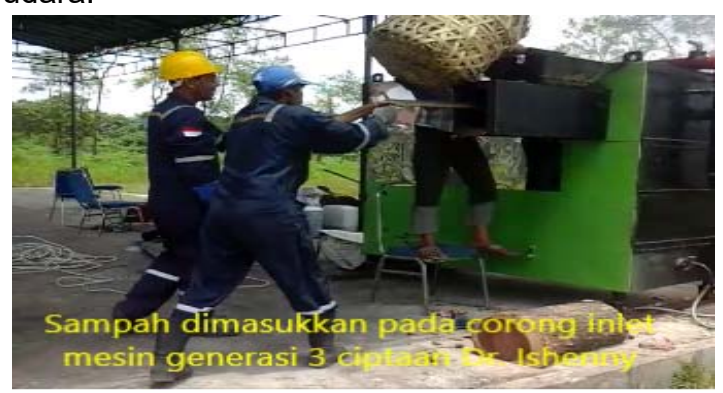

Gambar 8 Proses pemasukan sampah pada alat karbonisasi Dr. Ishenny's.

Sistem operasi prosedur penggunaan peralatan karbonisasi dilakukan secara efisien agar dapat menghasilkan produk yang optimal. Operator yang terlibat di dalam pengoperasian alat karbonisasi Dr. Ishenny's harus mendapat sertifikasi kompetensi dari Inkubator Campus Hijau Pusat Penelitian dan Pelatihan Teknologi Internasional Doktor Ishenny (ICH-LP3TIDI). 


\section{HASIL DAN PEMBAHASAN}

Teknologi karbonisasi memberikan hasil yang positif untuk pemakaian dan penerapannya di rumah sakit umum Kota Langsa Aceh. Perbedaan teknologi karbonisasi dan insenerator, dapat dilihat pada Tabel 2.

Tabel 2 Perbandingan hasil penerapan teknologi karbonisasi dan insenerator.

\begin{tabular}{|c|c|}
\hline Insenerator & Karbonisasi \\
\hline $\begin{array}{l}\begin{array}{l}\text { Memerlukan bahan } \\
\text { bakar, reaksi oksidasi } \\
\text { yang banyak }\end{array} \\
\text { membutuhkan udara, } \\
\text { terjadi pelepasan gas } \\
\text { dan partikel keudara } \\
\text { karena tekanan udara } \\
\text { yang tinggi di dalam } \\
\text { ruang bakar, terjadi } \\
\text { polusi ke lingkungan } \\
\text { sekitarnya (tidak sesuai } \\
\text { SNI terkait emisi) }\end{array}$ & $\begin{array}{l}\text { Limbah rumah sakit } \\
\text { sebagi bahan bakar } \\
\text { untuk reaksi thermo } \\
\text { kimia. } \\
\text { memerlukan rasio udara } \\
\text { dengan bahan bakar. } \\
\text { Tidak ada partikel yang } \\
\text { keluar dari proses } \\
\text { karbonisasi, dan ramah } \\
\text { lingkungan } \\
\text { (memenuhi persyaratan } \\
\text { SNI) }\end{array}$ \\
\hline $\begin{array}{l}\text { Biaya operasinya mahal, } \\
\text { gunakan bahan bakar, } \\
\text { dengan perkiraan }(0,21 \\
\text { x } 20 \mathrm{KVA} \times \mathrm{Rp} 8.000 \times \text { x } \\
24 \text { jam }=\text { Rp. } 804.400, \\
\text { untuk operasi selama } 24 \\
\text { jam }\end{array}$ & $\begin{array}{l}\text { Limbah sebagai bahan } \\
\text { bakar, dalam } 1 \text { kali } \\
\text { proses hanya butuh } 100 \\
\text { ml BSF (Rp } 150.000) \text {, } \\
\text { operasi selama } 24 \text { jam }\end{array}$ \\
\hline $\begin{array}{l}\text { Alat control mahal, } \\
\text { sangat komplek dalam } \\
\text { mengontrol efisiensi } \\
\text { pembakaran dan gas } \\
\text { buangnya }\end{array}$ & $\begin{array}{l}\text { Alat pengukur suhu dan } \\
\text { tekanan serta alat } \\
\text { pengatur sirkulasi air, } \\
\text { bisa dengan alat yang } \\
\text { manual }\end{array}$ \\
\hline $\begin{array}{l}\text { Memerlukan cerobong } \\
\text { yang tinggi, partikel } \\
\text { carbon dan abu yang } \\
\text { berukuran nano meter } \\
\text { tetap bisa keluar dan } \\
\text { membahayakan } \\
\text { kesehatan dan } \\
\text { lingkungan sekitarnya }\end{array}$ & $\begin{array}{l}\text { Tidak perlu cerobong } \\
\text { karena tidak ada asap } \\
\text { yang keluar, semua } \\
\text { proses reaksi sempurna } \\
\text { sehingga semua partikel } \\
\text { disirkulasikan jadi asap } \\
\text { cair dan pupuk cair } \\
\text { (memenuhi persyaratan }\end{array}$ \\
\hline $\begin{array}{l}\text { (tidak memenuhi } \\
\text { persyartan } \text { SNI terkait } \\
\text { emisi) }\end{array}$ & SNI terkait emisi) \\
\hline $\begin{array}{l}\text { Efisiensi pada ruang } \\
\text { pembakaran } 40 \%\end{array}$ & $\begin{array}{l}\text { Efisiensi ruang } \\
\text { pembakaran } 98 \%\end{array}$ \\
\hline $\begin{array}{l}\text { partikel racun akan } \\
\text { lepas ke udara }\end{array}$ & $\begin{array}{l}\text { Tidak ada partikel racun } \\
\text { yang keluar (memenuhi }\end{array}$ \\
\hline $\begin{array}{l}\text { (tidak memenuhi } \\
\text { persyartan SNI terkait } \\
\text { emisi) }\end{array}$ & $\begin{array}{l}\text { persyaratan SNI terkait } \\
\text { emisi) }\end{array}$ \\
\hline $\begin{array}{l}\text { Desain pada umumnya } \\
\text { adalah cylindrical } \\
\text { karena beroperasi pada } \\
\text { suhu tinggi dan tekanan } \\
\text { tinggi. }\end{array}$ & $\begin{array}{l}\text { Desain } \\
\text { karbonisasi adalah } \\
\text { cubical tapi mampu } \\
\text { beroperasi pada suhu } \\
700-1000^{\circ} \mathrm{F} \text {, tekanan } \\
\text { normal. }\end{array}$ \\
\hline
\end{tabular}

\begin{tabular}{|c|c|}
\hline Insenerator & Karbonisasi \\
\hline $\begin{array}{l}\text { Tidak bisa menurunkan } \\
\text { energi aktifasi sehingga } \\
\text { suhu pemanasan tinggi } \\
\text { diatas } 1000^{\circ} \mathrm{F}\end{array}$ & $\begin{array}{l}\text { Menurunkan energi } \\
\text { aktifasi sampah/limbah } \\
\text { sehingga terjadi reaksi } \\
\text { thermo kimia secara } \\
\text { sempurna pada suhu } \\
700^{\circ} \mathrm{F} \text { dan tekanan } \\
\text { normal } 1 \mathrm{~atm}\end{array}$ \\
\hline $\begin{array}{l}\text { Teknologi yang tidak } \\
\text { memenuhi persyarat -an } \\
\text { SNI yang terkait emisi, } \\
\text { tidak memberi jawaban } \\
\text { akan kebutuhan }\end{array}$ & $\begin{array}{l}\text { Teknologi masuk dalam } \\
\text { persyaratan SNI yang } \\
\text { terkait emisi, tidak } \\
\text { memberi jawaban akan } \\
\text { kebutuhan teknologi }\end{array}$ \\
\hline teknologi & pada persyaratan SNI \\
\hline persyaratan & $3242: 2008, \quad$ SNI \\
\hline $3242: 2008$ & $14001-2005$, SNI 19- \\
\hline $14001-2005, \quad$ SNI 19- & $14004-2005$, SNI 19- \\
\hline $\begin{array}{l}\text { 14004-2005, SNI 19- } \\
19011-2005\end{array}$ & $19011-2005$ \\
\hline
\end{tabular}

Pengolahan sampah dengan sistem karbonisasi telah memberikan manfaat lingkungan yang bersih dan juga peningkatan pendapatan dari sampah menjadi produk yang bernilai ekonomi. Manfaat teknologi karboniasai sebagai berikut:

\section{a. Manfaat bidang lingkungan}

Pengolahan limbah rumah sakit dilakukan sesuai dengan jadwal membersihkan dan mengumpulkan limbah rumah sakit dan limbah langsung di proses, sehingga dari tempat pembuangan sementara di rumah sakit dan memberikan manfaat sebagai berikut: (1) limbah langsung diolah menjadi karbon, (2) lingkungan bebas dari cemaran limbah rumah sakit, (3) tidak ada air lindi yang akan mencemari, (4) lingkungan rumah sakit sehat akan berdampak pada kesehatan pasien, (5) pengolahan sampah tanpa melakukan pemisahan sampah organik dan anorganik sehingga mempermudah proses olahan sampah, sesuai dengan SNI yang terkait dengan manajemen pengolahan lingkungan yaitu SNI 19-14001-2005, SNI 19-14004-2005, dan SNI 19-19011-2005.

Produk yang dihasilkan dari proses karbonisasi pengolahan sampah yang bermanfaat dan memiliki nilai ekonomi adalah: (1) biokar sebesar 5-10 \%, (2) asap cair $1 \%$ dan (3) pupuk organik cair 5\%. Sisanya sekitar $85 \%$ adalah limbah rumah sakit yang tidak bernilai, tetapi dapat dijadikan pendapatan tambahan untuk petugas kebersihan karena proses karbonisasi menghasilkan produk yang bernilai ekonomi.

\section{b. Manfaat bidang pertanian}

Biokar yang dihasilkan bersifat nano, memiliki beberapa sifat yang menguntungkan karena dapat menyediakan suplai makanan dan 
minuman yang cukup bagi kesehatan tanaman sawit.

Aplikasi pemanfaatan biokar sebagai media tanam, memberikan manfaat sebagai berikut (Plaza dkk, 2016): (Liu dkk, 2016) (a) mengembalikan kesuburan tanah pada $\mathrm{pH}$ : 7.007.50. (b) meningkatkan kandungan karbon tanah yang kaya oksigen. (c) menyimpan air dalam tanah. (d) menghasilkan nitrogen (Urea) melalui proses aktivitas mikro tanah. (e) meningkatkan porossitas tanah sehingga akar dapat menembus ke tanah lebih dalam. (f) meningkatkan produktivitas tanaman. (g) memperpendek usia panen tanaman. (h) menghapus penggunaan pupuk kimia. (i) mengurangi hama tanaman. (j) meningkatkan kualitas produk pertanian menjadi kualitas organik dan (k) meningkatkan pendapatan petani.

Asap cair mengandung komponen seperti fenol, asam organik dan karbonil yang berfungsi sebagai antibakteri, anti jamur dan koagulan (Jayanudin dan Suhendi, 2012), (Lingbeck dkk. 2014). Pupuk cair organik, kaya dengan kandungan karbon dapat di manfaatkan menjadi pupuk organik, dan akan menjadi cikal bakal pertanian organik.

Penerapan biokar, asap cair dan pupuk cair telah diterapkan pada tanaman padi, sayuran dan juga tanaman sawit dan rata rata dapat meningkatkan produksi $30 \%$ sampai dengan $100 \%$, tergantung pada jenis tanamanya, tanaman terhindar dari serangan mikroorganinsme yang dapat menghambat pertumbuhan dan pembuahan.

Penerapan biokar pada tanaman padi di Kota Langsa Aceh, menghasilkan padi dari 3 ton/ha menjadi 10 ton/ha. Aplikasi pada tanaman sayuran, proses pemanenan yang cepat dan subur dapat menghasilkan sayuran senilai $\mathrm{Rp}$. 20.000.000/ha/tahun dan pada tanaman sawit dapat meingkatkan produksi tandan buah segar sebesar $100 \%$ dan menjadikan sawit yang sakit terserang cendawan dapat segera dipulihkan dalam waktu 2 bulan.

\section{Manfaat bidang Konstruksi}

Biokar dari hasil proses karbonisasi sampah bisa dimanfaatkan sebagai bahan baku untuk pembuatan bata karbon ringan atau BATAKAR (Gupta dkk, 2018). BATAKAR tersebut telah diaplikasikan sebagai bahan konstruksi bangunan rumah dengan ukuran $36 \mathrm{~m}^{2}$ di Kota Langsa Aceh.

\section{KESIMPULAN}

Teknologi karbonisasi berbeda prosesnya dengan teknologi insinerator yang selama ini digunakan sebagai standar mutu penanganan limbah B3 rumah sakit, sesuai SNI 3242:2008. Teknologi karbonisasi menyelesaikan sampah tanpa menimbulkan polusi pada lingkungan dan mengubah sampah menjadi biokar, asap cair dan pupuk cair yang bermanfaat untuk memperbaki lingkungan dan bernilai ekonomi serta dimanfaatkan pada bidang pertanian dan konstruksi, teknologi yang mampu menyelesaikan limbah B3 rumah sakit dan tidak emsi gas buang sehingga juga memenuhi persyaratan SNI yang terkait dengan gas buang.

Limbah dengan alat karbonisasi menjadi produk yang bernilai ekonomi seperti biokar, asap cair dan pupuk cair serta tidak menghasilkan asap sehingga tidak terjadi polusi udara sedangkan dengan alat insinerator sampah/limbah jadi debu dan sebagian partikel terbuang ke udara yang menyebabkan polusi udara. Teknologi karbonisasi ini dapat dipertimbangkan sebagai masukan untuk revisi SNI yang berlaku saat ini dalam meningkatkan mutu penanganan limbah rumah sakit.

\section{UCAPAN TERIMA KASIH}

Ucapan terima kasih kepada Ketua Inkubator Campus Hijau - Lembaga Pusat Penelitian dan Pelatihan Teknologi Internasional Doktor Ishenny (ICH-LP3TIDI) dan pihak manajemen Rumah Sakit Umum Langsa Aceh sebagai tempat penelitian.

\section{DAFTAR PUSTAKA}

Aleluia, J and P Ferrao. (2016). Characterization of urban waste management practices in developing Asian countries: A new analytical framework based on waste characteristics and urban dimension. Waste Management 58. 415-429.

Asmadi, (2013). Pengelolaan Limbah Medis Rumah Sakit. Gosyen Publishing Yogyakarta.

Badan Standarisasi Nasional. SNI 19-7117.2(2005). Emisi gas buang - Sumber tidak bergerak - Bagian 2: Penentuan lokasi dan titik-titik lintas pengambilan contoh uji partikel.

Badan Standarisasi Nasional. SNI 19-14001(2005). Sistem manajemen lingkungan Persyaratan dan panduan penggunaan. 
Badan Standarisasi Nasional. SNI 19-19011(2005). Panduan audit sistem manajemen mutu dan/atau lingkungan.

Badan Standarisasi Nasional. SNI 19-14004(2005). Sistem manajemen lingkungan Panduan umum tentang prinsip, sistem dan teknik pendukung.

Badan Standarisasi Nasional. SNI 3242:2008). Pengelolaan sampah di Pemukiman.

Cha, JS., SH Park., AC Jung., C Ryu., JK Jeo., MC Shin, YK Park. (2016). Production and utilization of biochar: A review. Journal of Industrial and Engineering Chemistry 40. 1-5.

Chen, X., X Ma, X Peng, Y Lin, Z Yao. (2018). Conversion of sweet potato waste to solid fuel via hydrothermal carbonization. Bioresource Technology 249, 900-907.

Depkes RI, ,(2006). Pedoman Penatalaksanaan Pengelolaan Limbah Padat dan cair di Rumah Sakit, Bakti Husada, Jakarta.

Damanhuri, E. (2005). Some Principal Issues On Municipal Solid Waste Management In Indonesia, in In Expert Meeting on Waste Management in Asia-Pacific Islands, Tokyo Oct (Vol. 2729).

Gupta, S., HW Kua, CY Low. (2018). Use of biochar as carbon sequestering additive in cement mortar. Cement and Concrete Composites. 87. 110-129.

I.M. Noor, Badrul M. J, Brahim Si Ali, M. Hasan, K.B. Ramachandran, (2012)., New invention of Bio-fuel Production from palm oil mill effluent using bioprocess., Carbon capture daily report, Biofuel: P: 1-17.

Jayanudin dan E. Suhendi. (2012). Identifikasi Komponen Kimia Asap Cair Tempurung Kelapa dari Wilayah Anyer Banten, Vol 4, No.1 Jurnal Agroekoteknologi.

Keputusan Kepala Bapedal No. 205 tahun 1996 tentang Pedoman Teknis Pengendalian Pencemaran Udara Sumber Tidak Bergerak.

Keputusan Menteri Kesehatan 1204/MENKES/SK/X/2004 Persyaratan Kesehatan Rumah Sakit.

R.I. Nomor tentang Lingkungan

Klauck, CG., A Giacobbo, CG Altenhofen, LB Silva, A Meneguzzi, AM Bernardes, MAS Rodrigues. (2017). Toxicity elimination of lanfill leachate by hybrid processing of advanced oxidation process and adsorption. Environmental Technology \& Innovation 8, 246-255.
Lingbeck, JM., P Cordero, CA Obryan, MG Johnson, SC Ricke, PG Crandall. (2014). Functionality of liquid smoke as an allnatural antimicrobial in food preservation. Meat Science 97. 197-206.

Liu H., S Kong, Y Liu, H Zeng. (2012). Pollution control technologies of dioxins in municipal solid waste insenerator. Procedia Environmental Sciences 16, 661-668.

Liu, Y., H Lu, S Yang, Y Wang. (2016). Impacts of biochar on rice yield and soil properties in waterlogged paddy for two crop seasons. Field Crops Research 191. 161167.

Lohri, CR., HM Rajabu, DJ Sweeny, C Zurbrugg. (2016). Char fuel production in developing countries $-A$ review of urban biowaste carbonization. Renewable and Sustainable Energy Reviews 59, 15141530.

Lukas, A, S. Ngudiwaluyo, I.M Noor dan P. Natsir, (2017) Aplikasi Teknologi Radiasi Panas Pada Pengolahan Sawit Terpadu, Jurnal Industri Hasil Perkebunan Vol 12. No 2, Makasar

Matsakas, L., Q Gao, S Jansson, U Rova, P Christakopoulos. (2017). Green conversion of municipal solid wastes into fuels and chemicals. Electronic Journal of Biotechnology. 26. 69-83.

Plaza, C., B. Giannetta, JM. Fernadez, EG. Lopez-de-Sa, A. Polo, G. Gasco, A. Mendez, C. Zaccone. (2016). Response of different soil organic matter pools to biochar and organic fertilizers. Agriculture, Ecosystems and Environment 225. 150159.

Setiyono. (2001). Dasar Hukum Pengelolaan Limbah B3. Jurnal Teknologi Lingkungan. Vol. 2, No. 1. 72-77.

Shi, D., C Hu, J Zhang, P Li, C Zhang, X Wang, H Ma. (2017). Silicon-aluminium additives assisted hydrothermal process for stabilization of heavy metals in fly ash from MSW incineration. Fuel Processing Technology 165, 44-53.

Wang, Q., K Han, J Gao, H Li, C Lu. (2017). The pyrolysis of biomass briquettes: Effect of pyrolysis temperature and phosphorus additives on quality and combustion of bio-char briquettes. Fuel 199. 488-496.

Yan, M., X Li, J Yang, T Chen, S Lu, AG Buekens, K Olie, J Yan. (2012). Sludge as dioxins suppresant in hospital waste 
Jurnal Standardisasi Volume 20 Nomor 2, Juli 2018: Hal 129 - 138

\section{incineration. Waste Management 32}

1453-1458. 